\title{
Evaluating research proposals
}

SIR - Peer review is widely used for evaluating research proposals. But bibliometric indicators are also occasionally used. We assume that highly qualified teams will submit high quality proposals, which will be recognized as such by the peer review procedure of the Dutch Technology Foundation (STW). We expect these highly qualified teams to have high visibility in international journals, their publications having a relatively high rate of citation. And we expect that these highly qualified teams will come up with original research proposals.

Working with a random sample of 75

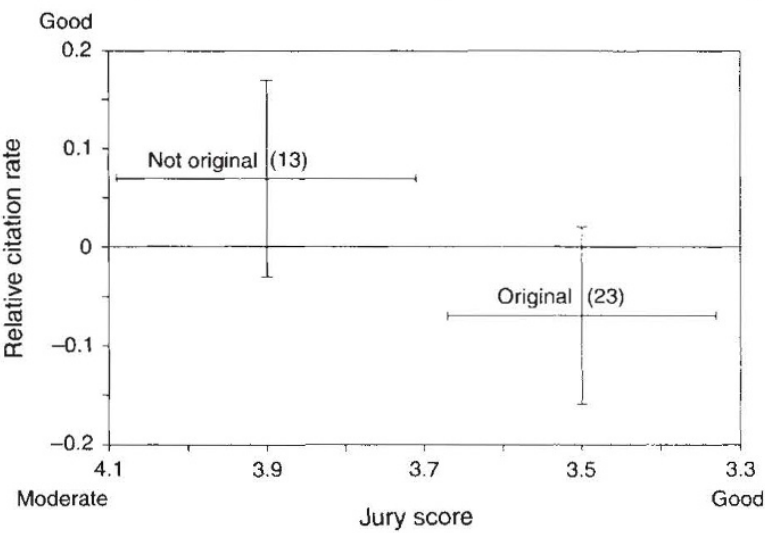

proposals (relating to applicationorientated research) submitted to STW between 1989 and 1990, we compared the results of peer review (as practised by STW) with the results of citation counting analysis (as practised by the Centre for Science \& Technology, CWTS). We were curious to discover whether the two methods would give approximately the same ranking for originality.

CWTS collected bibliometric data about the publications of the team members who had submitted the 75 proposals and calculated citation-based indicators. CWTS worked with two particular indicators: citations per publication (CPP) and the journal citation score mean (JCSm). CWTS calculated, first, the average CPP for the members of each research team over a three-year period, and, second, the JCSm over all the journals in which team members had published. A 'relative' citation rate was arrived at by $\log (\mathrm{CPP} /$ JCSm). This rate shows whether the team members' performance is lower (score $<0$ ) or higher (score $>0$ ) than the international average for the field. For 14 teams out of the 75, CWTS found no citations, so the relative citation rate did not exist. These proposals were not included in the further analysis.

STW's system, introduced in 1981, operates as follows: when a research proposal is submitted, at least five peers are invited to give well-founded comments. The principal investigator is asked to react to these comments. Next, a jury of 12 people, all highly qualified but not experts in the field of the proposal, is required to rate a group of 20 proposals on the basis of the peer comments and the principal investigator's defence. The jury ratings are then averaged to obtain a score for the scientific quality and the potential usefulness of each proposal. Only the scientific quality marks are referred to as 'the jury score'. The jury score can range from 9 (poor) to 1 (excellent).

On the basis of the detailed peer comments, STW divided the proposals into three categories: 'original', 'not original' and 'in between'. For proposals to be ranked as 'original' and 'not original', the five peers had to be unanimous in their verdict (which is given independently of each other).

The figure summarizes the results of the two methods. As can be seen, there is a considerable discrepancy: the jury score for the research proposals was 'good', whereas the 'relative' citation rate was only 'moderate'.

Good The conclusion of this study must therefore be that although citation rates may well be valuable indicators of the impact of a team's past performance, they are not necessarily reliable indicators of the originality of research proposals, particularly when these relate to application-orientated research.

Frans C. H. D. van den Beemt

Technology Foundation (STW),

POBOX 3021,

3509 GA Utrecht, The Netherlands

Anthony F. J. van Raan

Centre for Science \& Technology (CWTS), POBox 9555,

2300 RB Leiden, The Netherlands

\section{Whaling error}

SIR - You published recently (Nature 374, 587; 1995) a report headed "Error re-opens 'scientific' whaling debate".

The error in question, however, relates to commercial whaling, not to scientific whaling. Although Norway cites science as a basis for the way in which it sets its own quota, scientific whaling means something quite different, namely killing whales for research purposes. Any member of the International Whaling Commission (IWC) has the right to conduct a research catch under the International Convention for the Regulation of Whaling, 1946. The IWC has reviewed new research or scientific whaling programmes for Japan and Norway since the IWC moratorium on commercial whaling began in 1986. In every case, the IWC advised Japan and Norway to reconsider the lethal aspects of their research programmes. Last year, however, Norway started a commercial hunt in combination with its scientific catch, despite the IWC moratorium.

Norway is not bound by the IWC moratorium because it entered an objection when the moratorium was adopted. Early this year, the government of Norway announced that it was setting a commercial quota of 301 minke whales for the 1995 season. (No research catch is scheduled for 1995.) The 1995 hunt of 301 whales is the same number as was set in 1994 for the combined research and commercial catches. Norway's commercial whaling quota is said to be calculated using the IWC's Revised Management Procedure (RMP) combined with the Scientific Committee's 1992 abundance estimate of 86,700 minke whales in the northeast Atlantic. The RMP, on which the IWC Scientific Committee (SC) has worked for a number of years, was accepted in principle by the IWC Commission in 1994, but it has not yet been applied to quotas for commercial whaling. Norway's setting of a commercial quota is completely independent.

The abundance estimate of northeast Atlantic minke whales is now in question (as noted in Nature 374, 587; 1995). At this year's meeting of the IWC SC, the methodology for estimating the abundance of this population will be reviewed in detail. Now that this abundance estimate is in question, Norway (using a new abundance estimate of 69,900 ) has reduced its 1995 quota by 23 per cent to 232 . In fact, Norway's commercial hunt started on 2 May (six days before the start of the IWC $\mathrm{SC}$ review of the abundance estimate). Is Norway's unilateral action a rush to allow its whalers to kill the maximum number of whales before the IWC SC (which has been meeting 8-20 May 1995) provides a revised abundance estimate?

Robert L. Brownell Jr

Southwest Fisheries Science Center, POBOX 271,

La Jolla, California 92038, USA

\section{Einstein's debt}

SIR - In a recent lecture in the Netherlands on "What remains to be discovered?", your editor John Maddox said that Einstein should have acknowledged more frankly than he actually did his debt to Maxwell, Lorentz and Poincaré.

At Lorentz's funeral, Albert Einstein said: "To me he meant more than anybody I ever met in my life" (Leo Beek, Dutch Pioneers of Science, 1985).

Michaël W.J. van den Brink

The Hague, The Netherlands 